Revista de la red interuniversitaria de estudios sobre las literaturas rioplatenses contemporáneas en Francia

$18 \mid 2018$

El río y la ciudad

\title{
El río y los juegos acuáticos como espectáculo de
} masas

Alexis A. Chausovsky

(2) OpenEdition

Journals

Edición electrónica

URL: http://journals.openedition.org/lirico/5641

DOI: $10.4000 /$ lirico.5641

ISSN: 2262-8339

Editor

Réseau interuniversitaire d'étude des littératures contemporaines du Río de la Plata

\section{Referencia electrónica}

Alexis A. Chausovsky, "El río y los juegos acuáticos como espectáculo de masas », Cuadernos LIRICO [En línea], 18 | 2018, Puesto en línea el 12 octubre 2018, consultado el 20 abril 2019. URL : http:// journals.openedition.org/lirico/5641 ; DOI : 10.4000/lirico.5641

Este documento fue generado automáticamente el 20 abril 2019.

\section{(c) (†) $\odot$}

Cuadernos LIRICO está distribuido bajo una Licencia Creative Commons Atribución-NoComercialSinDerivar 4.0 Internacional. 


\title{
El río y los juegos acuáticos como espectáculo de masas
}

\author{
Alexis A. Chausovsky
}

\section{Introducción}

1 En su libro Del pasado entrerriano. Cuentos y anécdotas paranaenses, publicado en 1941 y reeditado por EDUNER en 2017, Francisco Delfín Segovia retrata las transformaciones de la ciudad de Paraná en el umbral de los siglos XIX y XX. El autor pone la lupa en las variaciones de los ámbitos educativos, tensando un arco que va desde los días de concurrencia a la escuelita de la maestra Valentina, docente y cigarrera, que enseñaba en su rancho a un grupo de niños utilizando una cartilla para que aprendan el abecedario de memoria, hasta la asistencia a la Escuela Normal, de cursos numerosos y educadores anglosajones convocados por Sarmiento. El libro nos brinda, asimismo, viñetas dedicadas a las costumbres y al ocio.

2 El capítulo "Los deportes de antaño" invita a reflexionar sobre los usos lúdicos del río por parte de los ciudadanos:

En Paraná y en muchos otros centros de población de la provincia, los deportes más generalizados fueron la equitación y la natación. Los grandes ríos que limitan las tres cuartas partes del territorio entrerriano y los ríos interiores y arroyos que en determinadas épocas del año ofrecen caudalosas corrientes, han sido factores del deporte natatorio, originado primeramente por necesidades de la vida campera y por previsión de las luchas armadas en que los entrerrianos tuvieron que intervenir. [...] El remo fue un deporte que tuvo gran impulso hace más de cuarenta años, mientras hoy se ve limitado a los clubs náuticos ${ }^{1}$.

Advertimos, por un lado, la manera en que una tarea desarrollada en el agua, la natación, pasa de ser una condición para la supervivencia a un acto propio de la vida bella, en una suerte de metamorfosis de la zôé al bios, con la ampliación de la urbe y la satisfacción de los requerimientos básicos de sus habitantes. Por otro lado, divisamos cómo se produce la delimitación de ciertas actividades lúdicas de acuerdo con la institucionalización de las 
prácticas de entretenimiento. De manera sutil, silenciosa, los deportes acuáticos se cuelan en el despliegue de una ciudad que pugna por incluirse en los caminos del progreso.

A partir de la lectura, nos preguntamos de qué modo se producen los vínculos entre el río y la ciudad en función del desarrollo de juegos ${ }^{2}$, deportes y actividades recreativas (que no son lo mismo, pero que constantemente van de la mano). ¿Qué incidencia en la planificación urbana poseen las diversiones? Si la percepción del espacio y el tiempo varía históricamente, y a la vez se modifican las maneras de entender lo lúdico, ¿cómo se superponen en las ciudades los sitios de juego construidos en diferentes épocas? ¿Cómo se estructuran estas actividades según la conformación de las clases sociales? ¿Acaso podríamos hablar, siguiendo a Rancière, de la partición de lo sensible al posar nuestra mirada en las relaciones entre el río y la ciudad? Si es factible rastrear la historia del playground, la tierra de juego, como una referencia para observar y diseñar la ciudad a inicios y mediados del siglo XX en megalópolis como Nueva York o Ámsterdam, ¿qué lugar le cabe al río como espacio de juegos, ya sea en poblaciones pequeñas o medianas? Todos estos interrogantes nos transportan, a la vez, a otra pregunta: ¿puede el río considerarse como una plataforma en la que los juegos acuáticos y las diversiones se vuelvan objetos de atracción para las masas de espectadores en la ciudad?

En el presente trabajo nos proponemos compartir una hipótesis, una respuesta posible para algunos de estos interrogantes: el río tiene un momento de singular eclosión como escenario de espectáculos y diversiones para las masas en una incipiente industria cultural en 1900, año en que coinciden la Exposición Universal y los Juegos Olímpicos en la ciudad de París, adquiriendo el Sena un rol protagónico. Nos referimos a un ejemplo, entre otros, de la configuración del río como sitio de entretenimientos. A partir de lo dicho por Giorgio Agamben en Signatura rerum, definimos al ejemplo como aquello que se despoja de un conjunto de relaciones precisamente por su inclusión y participación en ellas. El ejemplo se excluye exponiendo su inclusión (siendo el reverso de la excepción, que supone la inclusión de un elemento por su exclusión de esos vínculos)3. El derrotero que seguiremos a partir de nuestra conjetura será guiado por una mirada infantil, que asomó en los recuerdos de la niñez de Segovia y reaparecerá, como un pequeño que juega a las escondidas, saliendo de improviso para llevarnos consigo.

\section{Disquisición sobre el espectáculo}

6 La vastedad de las producciones científicas y filosóficas en torno a la noción de espectáculo excede aquello que aquí buscamos estudiar. Una exploración bibliográfica meticulosa nos llevaría a detenernos en el teatro griego y las diversiones en el Imperio Romano; la carta sobre los espectáculos de Rousseau a D’Alembert es una referencia bibliográfica necesaria (a la que acudiremos hacia el final de este escrito). Apenas transitaremos brevemente algunas discusiones para dejar asentada nuestra posición al respecto.

7 Más allá de acudir a la proveniencia etimológica del vocablo "espectáculo" (del latín spectāre, esto es: contemplar), no podemos dejar de acudir al emblemático y polémico escrito de Guy Debord sobre Las sociedades del espectáculo. El inicio del texto, que se ha convertido en una suerte de adagio, indica que

en las sociedades dominadas por las modernas condiciones de producción, la vida es presentada como una inmensa acumulación de espectáculos. Todo lo que se ha vivido directamente se ha tornado una representación. Las imágenes separadas de 
cada aspecto de la vida se combinan en una misma pantalla en la que la unidad de aquella vida no puede recobrarse. Imágenes fragmentadas de la realidad se reagrupan en una nueva unidad como un pseudo-mundo separado al que sólo se puede mirar ${ }^{4}$.

Debord procede a una interpretación neofeuerbachiana (siguiendo a Ágnes Heller, podemos decir que se trata de otro autor que ha cruzado el feuer-bach) para dar cuenta de la escisión del ser humano frente a un mundo que se la presenta como un objeto plagado de imágenes a las que sólo puede contemplar. La ajenidad entre el sujeto que mira y las imágenes que son miradas signa el conjunto de relaciones entre los seres humanos y su entorno ${ }^{5}$.

Entre las recepciones más singulares y prolíficas de la obra de Debord se encuentra la lectura de Giorgio Agamben. El filósofo italiano lleva a un extremo las hipótesis de La sociedad del espectáculo e incluso habla de la religión espectacular como la divisa de las sociedades de capitalismo altamente desarrollado. La religión espectacular es la forma plena de separación, dominada por el consumo ${ }^{6}$, que supone eminentemente la posibilidad de "tener" algo, pero sin despojarlo de las reglas que lo dominan y lo sitúan en el mercado, como una imagen intocable. Ello demuestra que el hombre moderno ya no sabe jugar, no disuelve las relaciones dadas, y por eso multiplica incesantemente juegos nuevos y viejos: "En el juego, en los bailes y en las fiestas el hombre busca, de hecho, desesperada y obstinadamente, justo lo contrario de lo que podría encontrar: la posibilidad de volver a acceder a la fiesta perdida". ${ }^{7}$ De hecho, en Medios sin fin, dedicado a Debord, el espectáculo se caracteriza como lenguaje, la comunicabilidad misma y hasta el ser lingüístico del hombre.

Bien sabemos que Jacques Rancière toma distancia en El espectador emancipado de los postulados de Debord y plantea una reconfiguración de la concepción del espectador a la luz de sus propuestas en El maestro ignorante. Rancière afirma que, desde la mirada de la emancipación, el espectador, como el alumno que no es guiado por un maestro embrutecedor, adquiere un papel activo, no determinado unilateralmente por las imágenes o las palabras que hacia él se proyectan.

El espectador también actúa, como el alumno o como el docto. Observa, selecciona, compara, interpreta. Liga aquello que ve a muchas otras cosas que ha visto en otros escenarios [...]. Compone su propio poema con los elementos del poema que tiene delante. Participa en la performance rehaciéndola a su manera [...] Así, son a la vez espectadores distantes e intérpretes activos del espectáculo que se le propone ${ }^{8}$.

11 La perspectiva de Rancière se permite despojar los términos de espectador y espectáculo de definiciones unívocas y estrechas. El espectador contempla, pero no es un mero objeto dispuesto y prefabricado como receptor pasivo de aquello que tiene enfrente. Dentro de sí guarda las potencialidades de la novedad, de lo que irrumpe imprevistamente en los modos de mirar y de sentir. $\mathrm{Y}$ así como no hay incidencias unilaterales de las imágenes hacia el espectador, este tampoco determina por completo lo que las imágenes significan. El espectador es un posible creador de lo nuevo a partir de las imágenes9.

12 En los parágrafos por venir tendremos como supuesto el modo en que Debord define al espectáculo y su recepción agambeniana, sin dejar a un lado por completo las apreciaciones de Rancière, pues la potencia de la figura del espectador emancipado nos detiene frente a simplificaciones e interpretaciones que clausuren la perspectiva. Advertiremos, incluso, que los espectáculos y las festividades masivas dan lugar a la aparición de lo imprevisto e inasible de antemano. 

juegos acuáticos como espectáculos de masas urbanos a partir de la confluencia de la Exposición Universal y los Juegos Olímpicos en el año 1900. Tanto las Exposiciones Universales como los Juegos olímpicos contribuyeron, con una serie de procesos, a la normalización del individuo espectador. Emergiendo desde el siglo XIX, las expresiones del embelesamiento europeo por el orden y el progreso marcaron los trabajos, las tareas cotidianas y también definieron una diversión que se volvía útil para el culto a la distracción al calor del despliegue del capitalismo. Tanto el libro de la naturaleza como el libro de la sociedad estaban expresados en caracteres matemáticos. La corporalidad de la población era racionalizada y organizada por el cálculo y la mensurabilidad, en un ambiente donde se comenzaba a hablar, precisamente, de la maquinaria social. La repartición de los cuerpos en tiempos y espacios específicos, así como por el señalamiento de las vías que tenía que seguir la mirada para contemplar el espectáculo, definieron cómo el ser humano comenzó a relacionarse en masa con su objeto de admiración. Estamos hablando, entonces, de la conformación primigenia de un mundo de pantallas en los albores de la sociedad del espectáculo, donde el río, en diferentes ocasiones, es una pantalla más, circunscribiendo la contemplación de las acciones que en ella se desenvuelven.

ra bien, las festividades urbanas masivas sólo pueden entenderse como tal si se atiende al contexto, al enlace de prácticas situadas que reconfigura a las ciudades en el siglo XIX. "Hacia 1860 el capitalismo de libre competencia estaba en su apogeo. Aún la mayoría de la población vivía en el campo, pero las ciudades industriales crecían vertiginosamente, con el trabajo de centenares de miles de obreros" ${ }^{10}$. En medio de estas transformaciones sociales, políticas, tecnológicas y estéticas, la ciudad se vuelve objeto de estudio de sí misma; el surgimiento de las ciencias sociales lo atestigua. Aún más, se vuelve paisaje de sí misma. La ampliación y la indefinición de los límites de la urbe dan lugar a un modo de relación con el espacio en el cual ya no sólo se mira desde la ciudad hacia sus afueras, o desde lo externo hacia el centro, sino que la urbe envuelve la mirada y los sentidos en su totalidad. Con tal viraje, destacado en los cambios históricos de la percepción -e inclusive que redefinen la percepción (basta remitirse a los estudios sobre percepción y apercepción de Wilhelm Wundt)- en Occidente, se produjeron también modificaciones en las maneras de circular, de esperar y de permanecer en cada lugar.

De hecho, el caminar mismo tiene aquí el color de una peregrinación secularizada. Se trata de una forma codificada del caminar; lejos de las ensoñaciones de un paseante solitario, se trata de quien se pliega a los movimientos compactos y útiles de la masa. La peregrinación tiene un inicio, un desarrollo y una finalización bien definidos. El peregrino siempre es un extranjero, pues al caminar nunca está en su propio lugar. "En cuanto se camina de verdad, día tras día se enfrenta uno a toda una serie de despedidas. Nunca se está muy seguro de regresar aquí o allá. Esta condición de partida alimenta la intensidad de la mirada"11. Las Exposiciones Universales y los Juegos Olímpicos adquieren entonces una relevancia mayúscula si se pretende investigar la participación del río en el acrecentamiento de las ciudades y su configuración como sitios de exhibición y entretención de la multitud. 


\section{En torno a la Exposición Universal de 1900}

16 A pesar de su enorme popularidad, ni las Exposiciones ni los Juegos Olímpicos han sido objeto de estudios sistemáticos en Ciencias Sociales y Humanidades. Si bien existen artículos especializados, no hay investigaciones de largo alcance que se hayan vuelto canónicas para su exploración. En el siglo XIX es Baudelaire uno de los primeros escritores en fijar su atención en las Exposiciones (antes lo había hecho Taine, con motivo de la primera Exposición, realizada en Londres en 1851 y en la que se construyó el Crystal Palace en Hyde Park). El poeta lírico desarrolla, recorriendo la Exposición de 1855, curioseando en los pabellones de países de diferentes rincones del planeta, un método de crítica de la idea moderna del progreso aplicada a las bellas artes.

Baudelaire, reconociendo asimismo que lo bello es siempre extraño y que en las Exposiciones se forja un desplazamiento de la vitalidad hacia su mecanización, mira con sospecha lo que allí sucede. En unas líneas que aparentan ser marginales pero revelan un gesto irónico, advierte:

Paso por alto la cuestión de saber si al hacer más delicada a la humanidad en proporción a los nuevos goces que le aporte, el progreso indefinido no se convertiría en su más ingeniosa y cruel tortura; si procediendo a la manera de una terca negación de sí mismo, no sería un modo de suicidio incesantemente renovado 12.

Con la ontología del presente que desenvuelve en su flanerie -modo de andar que aparece como contraposición al peregrinaje-, el poeta como crítico, sin abandonar su ámbito de juego y ofreciendo un notable carácter anticipatorio, describe el desamparo que se cierne sobre quienes se reúnen encantados en la exposición. Las Exposiciones Universales aparecen como la instancia que caracteriza los "cantos de experiencia" en la modernidad -o en la modernidad europea, al menos-, donde lo fugaz y lo permanente se entrecruzan y la percepción transita modificaciones acentuadas frente a la multiplicación inédita de dispositivos técnicos y productos infinitos e inasibles. Auguran así aquello que, en un clima muy cercano, Georg Simmel entiende como la tragedia de la cultura: todo está, como objeto de la mirada, ante un público en el cual se produce el deseo y que no se puede apropiar ni agenciar de todas las mercancías (incluso resignándose a ello) y se circunscribe al uso y consumo prefijados.

En una línea similar, entre los escritores latinoamericanos, José Martí y Rubén Darío (entre otros, además de Horacio Quiroga y, por supuesto, de Domingo Faustino Sarmiento) se ocuparon de relatar para el gran público lector lo sucedido en las Exposiciones. Martí retrata la Exposición Universal de París en 1889 en la publicación mensual La Edad de Oro. Asumiendo la perspectiva de los niños (incluso habla de "nosotros, los niños de América") y escribiendo para los pequeños, Martí recorre los pabellones de cada país, ensalza la galería de máquinas (a la cual le atribuye un artículo autónomo), el Palacio de los Niños y las diversiones de los panoramas. Esta exposición, en el centenario de la Revolución Francesa, es celebrada por el narrador como el momento de reunión de todos los pueblos del mundo, con más de cien mil visitantes diarios, en la tierra donde se despojó a los reyes del poder. Martí aprecia el Sena, en cuya orilla "vamos a ver la historia de las casas, desde la cueva del hombre troglodita, en una grieta de la roca, hasta el palacio de granito y ónix"13. El poeta cubano, que de hecho traza aparte un escrito sobre la historia del hombre a través de sus casas, destaca la convergencia de 
poblaciones y apunta que desde los puentes que pasan por arriba del Sena "se ven por todas partes los grupos de gente asombrada, que vienen de los edificios de orillas del río, donde está la Galería del Trabajo, en que cuecen los bizcochos en un horno enorme, y destilan licor del alambique de bronce rojo" ${ }^{14}$. Curiosamente, Martí no asistió a la Exposición de 1889, momento emblemático del triunfo del hierro en las construcciones y los ornamentos, exhibición de la recién construida Torre Eiffel, sino que escribe a partir de sus observaciones de litografías.

El enaltecimiento del cosmopolitismo que ofrece Martí constituye un rasgo también de Rubén Darío, quien presenció la Exposición de 1900 (a la que también asistió Horacio Quiroga) como cronista enviado por el diario La Nación. El artículo "En París", publicado en el periódico porteño el 20 de abril de ese año y reproducido al año siguiente en Peregrinaciones, aplaude la masividad de la exhibición con la metáfora acuática: "Ya la ola repetida de este mar humano ha invadido las calles de esa ciudad fantástica que, florecida de torres, de cúpulas de oro, de flechas, erige su hermosura dentro de la gran ciudad"15. A su vez, Darío registra la disposición de edificaciones y personajes en torno al río:

La calle de las Naciones aglomera sus vistosas fábricas en la orilla izquierda del Sena, y presenta, como sabéis, a los ojos, que se cansan, la multiplicidad de los estilos y el contraste de los caracteres [...]. El conjunto, en su unidad, contiene bien pensadas las divisiones, facilitando así el orden en la visita y la observación. El lado del Trocadero, el de los Campos Elíseos, el de la Explanada de los Inválidos, el de la orilla izquierda del Sena, el de la orilla derecha y el del Campo de Marte son puntos diversos con sus particularidades especiales y diferentes atractivos, y, vínculo principal entre orilla y orilla del río, tiende su magnífico arco, custodiado por sus cuatro pegasos de oro y adornado por sus carnales náyades de bronce, el puente Alejandro III. La unión total, la mágica villa de muros de madera ${ }^{16}$.

21 Darío ofrece a la lectura un cuadro preciso de cómo y dónde son ubicados los espectadores respecto del río y cómo el hormigueo de la multitud en estos festivales representa la delimitación del merodeo inútil. Si en la Exposición de 1889 la atención se centraba en las construcciones de hierro, esta se vincula con la exaltación del arte y el color de las naciones. El río aparece perfectamente delimitado y ubicado para que el paseo se torne armonioso y se lo contemple con regocijo.

En la pluma del poeta nicaragüense retorna, como lo reprimido que puja por manifestarse, la mirada infantil ( $\tan$ presente en la escritura de Martí). Darío, en un texto de mayo de 1900, donde observa la flora fantasmagórica de la plaza de l'Alma, los mascarones de los cabarets, y disfruta de la música en esa Babel que es asimismo la capital de la locura, argumenta que "como en el reino de los cielos, para estar aquí, es preciso ser un poco niño"17. Para disfrutar hay que despojarse de las restricciones del mundo adulto, ya sea retornando a la niñez o actualizando sus potencialidades. Darío busca la mirada infantil, que suele huir casi involuntariamente de lo legitimado, que se enfoca en y desde los rincones y se desentiende del movimiento de la gente para concentrarse en el envoltorio de una golosina o en el andar de un insecto. Ahora bien, vale decirlo: esos niños también son disciplinados celosamente por el entretenimiento de la ciudad. París, reconocida como un formidable casino, un establecimiento de diversiones y placeres, se transforma a su vez en el sitio que exhibe la distribución calculada de los cuerpos humanos congregados en ingentes cantidades, donde la masa no va a educarse, sino a divertirse.

Walter Benjamin caracteriza a las Exposiciones Universales en su exposé "París, capital del siglo XIX" como el lugar de peregrinación hacia el fetiche que es la mercancía. El filósofo 
berlinés no sólo ofrece sus reflexiones sobre las Exposiciones Universales en sus célebres proyectos sobre Baudelaire o en su trabajo sobre la protohistoria del siglo XIX conocido como el proyecto sobre los pasajes parisinos. En un fragmento algo marginal para las recepciones de su obra, la segunda "Ronda de juguetes en Berlín", relato radiofónico de 1931 dirigido específicamente a la audiencia infantil, Benjamin le pregunta a su audiencia:

“¿Habéis oído mencionar alguna vez la Exposición Universal de París, de la que se habló en toda Europa en el año 1900?" En todas las postales que se hicieron por aquel entonces con motivo de la Exposición se ve, al fondo de la ciudad de París, una gran rueda mecánica con quizá dieciséis cabinas sobre bisagras móviles. Esta rueda giraba lentamente, la gente se sentaba en las cabinas y contemplaba a sus pies la ciudad, el Sena y la Exposición hasta que se mareaban debido al doble movimiento ${ }^{18}$.

La modificación de perspectivas que otorgaba la singular construcción permitía mirar el río desde diferentes ángulos y, por eso, no podría ser entendida por nadie mejor que por los niños.

\section{Los Juegos Olímpicos y el río hacia el 1900}

Más allá de las distancias entre las escrituras de Martí y Darío en torno a las Exposiciones Universales (no hace falta más que apuntar sus diferentes interlocutores, las divergencias en sus modos de expresión a pesar de hablar en primera persona del plural y, claro está, los propósitos disímiles de los medios de comunicación en que publican), consideramos fundamental señalar las modificaciones que se producen entre sus respectivos contextos de enunciación. En 1895 los hermanos Lumière proyectaron la primera película cinematográfica. No se trata de una nimiedad para nuestro estudio, pues el cine, junto con los panoramas, los mirioramas, las litografías, los juguetes ópticos y la fotografía, constituye parte del conjunto de dispositivos técnicos que aportan -acompañando las reformas arquitectónicas y urbanísticas, a partir de la hausmannización- a la modificación del régimen escópico y a la estandarización de la mirada, lo cual se advierte con claridad en 1900.

Un año antes se inició en Francia la acusación a Dreyfus, donde la masa poblacional cobró un lugar central, sobre todo a partir del encubrimiento del error judicial y el antisemitismo por parte de los poderes judicial y ejecutivo. El cuadro de la población francesa, pasado poco más de un siglo de la Revolución, se mostraba particularmente quebradizo.

Se cometió un error judicial y desde entonces, para ocultarlo, ha habido que cometer todos los días un nuevo atentado al sentido común y a la equidad [...]. Ya no hay caso Dreyfus, ahora se trata de saber si Francia es todavía la Francia de los derechos humanos, la que ha otorgado la libertad al mundo, la que debía otorgarle justicia [...]. Dentro de algunos meses llegarán esos pueblos, y lo que van a encontrar es un inocente dos veces condenado, la verdad encarecida, la justicia asesinada [...]. ¿Vamos a permitir que nuestra Exposición Universal sea la tabernucha despreciable donde el mundo entero venga a divertirse? [...]. Necesitamos nuestro honor para saludar a los pueblos en una Francia restablecida y regenerada ${ }^{19}$.

La vociferación de Zola, descifrando el jeroglífico de una masa de ciudadanos que se inclinaba por las distracciones en lugar de la acción política, se consolidaba poco a poco, mientras aumentaban los crímenes gestados por el mismo gobierno. En un cuadro que ofrecía un país sumido en la indiferencia, se buscaron soluciones. 
Para muchos, el antídoto evidente ante este retroceso era un compromiso nacional con los deportes. Un cuerpo saludable podría dejar a un lado la década perversa que afectó a la juventud francesa, como la luz solar que borra los caminos del lodo. Para otros, había un subtexto adicional: si Francia buscaba restaurar su lugar prominente en el mundo, tendría que enviar a la batalla a muchachos provenientes de los campos de juego y no de los bares y salones de baile de Montmartre ${ }^{20}$. parte un paranaense, José Benjamín Zubiaur, compañero de Francisco Delfín Segovia, y que tal vez haya tenido como referencia aquellos juegos acuáticos de infancia y adolescencia en el Paraná durante su participación. Zubiaur viajó a la Exposición Universal de 1889, donde conoció a Pierre de Coubertin, fundador del Comité Olímpico Internacional, quien lo invitó a participar. Años más tarde, cuando fue rector del Colegio de Concepción del Uruguay entre 1892 y 1899, Zubiaur introdujo la educación física en el sistema educativo formal argentino.

qual que las Exposiciones Universales, los Juegos Olímpicos constituyen la ocasión para que cada nación construya su relato y su historia, se enmascare para exponerse al mundo. Tales celebraciones tampoco han gozado de una atención persistente para su estudio, ni en las ciencias sociales ni en las humanidades (podría rastrearse, desde ya, la presencia de los deportes en la literatura). En el terreno de la filosofía encontramos apreciaciones marginales de Walter Benjamin, teniendo en mente los Juegos Olímpicos de Berlín en 1936. En los paralipómenos de la primera versión del célebre artículo "La obra de arte en la época de su reproductibilidad técnica", el filósofo alemán considera a los Juegos Olímpicos como exacerbación del valor de exhibición y como práctica delimitada por las mediciones:

El fundamento del deporte descansa sobre un sistema de prescripciones que, en última instancia, conducen a medir las modalidades de los comportamientos humanos por medio de criterios físicos elementales: la medida en segundos y centímetros [...]. La antigua forma agonal desaparece a los ojos vistas del ejercicio moderno del deporte [...]. Sin embargo, a diferencia del desempeño deportivo, el de la prueba mecanizada no puede ser objeto de exhibición, sin que por ello se restrinja su alcance social [...]. Los Juegos Olímpicos son reaccionarios ${ }^{21}$.

30 En este caso, además, se observa a los Juegos Olímpicos como una expresión más del neoclasicismo y el aparente retorno armonioso a una sociedad de bonhomía con la naturaleza en el orbe del altocapitalismo. Al margen: Susan Buck-Morss aclara que Hitler no tuvo su Exposición Universal, pero tuvo sus Juegos Olímpicos,

la nueva forma de espectáculo de masas que superaría a la exposición internacional en nuestra época (las exposiciones internacionales se habían vuelto poco rentables) [...]. Aquí, en lugar de las últimas maquinarias industriales, se exhibió la capacidad de los cuerpos humanos, que actuaron para una audiencia masiva. ${ }^{22}$

31 Los Juegos Olímpicos de 1900, que se desarrollaron durante todo el año y coincidieron en varios sitios con la Exposición Universal, tuvieron características singulares. En ellos se inauguraron las competencias femeninas y se consagró, en tenis, la primera campeona, Charlotte Cooper. Asimismo, fueron la ocasión para el inicio de ciertos deportes acuáticos. El río Sena, pantalla y lugar de espectáculos para la Exposición Universal, fue también el escenario donde se desarrolló un deporte que tenía creciente interés del público en Inglaterra y Francia: el remo. El río pasó a ser delimitado, encerrado, medido, procurando que su fluencia condicionara lo menos posible en las destrezas de los deportistas. Como había ocurrido en los Juegos Olímpicos de Atenas en 1896, las pruebas de natación se desarrollaron en un ambiente considerado natural: un recodo del río Sena lindero a la 
localidad de Asnières-sur-Seine, sitio de condiciones favorables, pues las aguas se encontraban aquietadas.

Entre el 11 y el 12 de agosto, siete especialidades, todas masculinas, se cumplieron en una "pileta" delimitada por botes, sogas y boyas. Lo curioso del programa fue que, junto a carreras "normales" como los 200, 1000 y 4000 metros estilo libre, se incluyeron competencias absurdas, como " 60 metros bajo el agua". En esta, apenas 2 de los 14 concursantes pudieron cumplir el objetivo: el resto debió salir a la superficie so riesgo de morir ahogado. El francés Charles de Vaudeville ganó el "oro" con un tiempo de 1:08,4, tres segundos menos que su compatriota André Six. Sin embargo, la mayor locura consistió en la prueba de "200 metros con obstáculos", que obligaba a los nadadores a pasar debajo de barriles. Esta contienda, más propia de un circo que de una olimpíada, tuvo como vencedor al australiano Frederick Lane, quien también había triunfado en los 200 metros libres ${ }^{23}$.

En este escenario, llamativo pero aparentemente sin fisuras, irrumpe, nuevamente, la figura del niño. No hablamos del niño que escrupulosamente observa lo que los demás desatienden ni el que se cuela en los rincones del público para merodear con una pequeña diversión. Tampoco es el que chapotea cerca de la orilla o se tira agua con sus compañeros de juego. Nos referimos a un niño que, transgrediendo (con permisos, es cierto) las reglas que le corresponden a la masa de espectadores, se convirtió en un enigmático protagonista de la historia de los juegos acuáticos.

En Asníères-sur-Seine también se realizaron las pruebas de remo, que tuvieron lugar por primera vez en los Juegos Olímpicos dado que en su primera edición, en Atenas en 1896, debieron ser suspendidas por inclemencias climáticas.

El 25 de agosto, al realizarse las preliminares de parejas con timonel, los holandeses Francois Antoine Brandt y Roelof Klein no quedaron conformes con su rendimiento. Si bien habían calificado para la final, habían sido ampliamente superados por la embarcación de la Societé Nautique de la Marne, que llevaba un niño como timonel. Del mismo modo, los botes de otras dos instituciones francesas -Rowing Club Castillon y Cercle Nautique de Reims- que se habían clasificado en la otra serie, llevaban un chico como guía. Ellos, en cambio, habían sido asistidos por su compatriota Hermanus Gerardus Brockmann, que era un muchacho de 28 años, mucho más grande y pesado. Esa noche, Brandt y Klein coincidieron en que, para tener posibilidades de ganar la competencia, debían reemplazar a su compañero por un nene que restara kilos al andar de su barca, bautizada Minerva Amsterdam. ${ }^{24}$

34 Al día siguiente, los holandeses buscaron entre el público hasta que hallaron un niño francés que había llegado al lugar junto a sus padres. El niño fue invitado de manera inmediata a sumarse al equipo. Los holandeses, con la autorización de los padres y los jueces de la competencia, incluyeron al pequeño en su embarcación y terminaron victoriosos. Luego de la premiación, los vencedores se tomaron una fotografía con el niño, que instantes después volvió con sus padres, desapareció entre la multitud y no regresó. No queda ningún registro del nombre o la edad del joven timonel, quien desde entonces es el ganador más joven de la historia de los Juegos Olímpicos y a la vez permanece en el anonimato.

Esta historia, que tuvo también al Sena como escenario para la gesta deportiva frente a la multitud, nos lleva a preguntarnos, entonces, qué ocurrió con el niño posteriormente. ¿Habrá peleado en la Primera Guerra Mundial? ¿Migró hacia algún país de América Latina? ¿Se habrá sumado, más tarde, a filas partisanas? ¿Se habrá constituido en un alto comerciante? ¿Adquirió fobia al agua? ¿Gobernó alguna ciudad? Lo cierto es que ese niño, que probablemente en ese año 1900 recorrió la misma exposición que Darío, divirtiéndose en los pabellones y en las orillas del río, nos aporta una asombrosa historia para pensar la 
relación entre el río y la ciudad, con los juegos y las diversiones que los habitan, desde otro rincón.

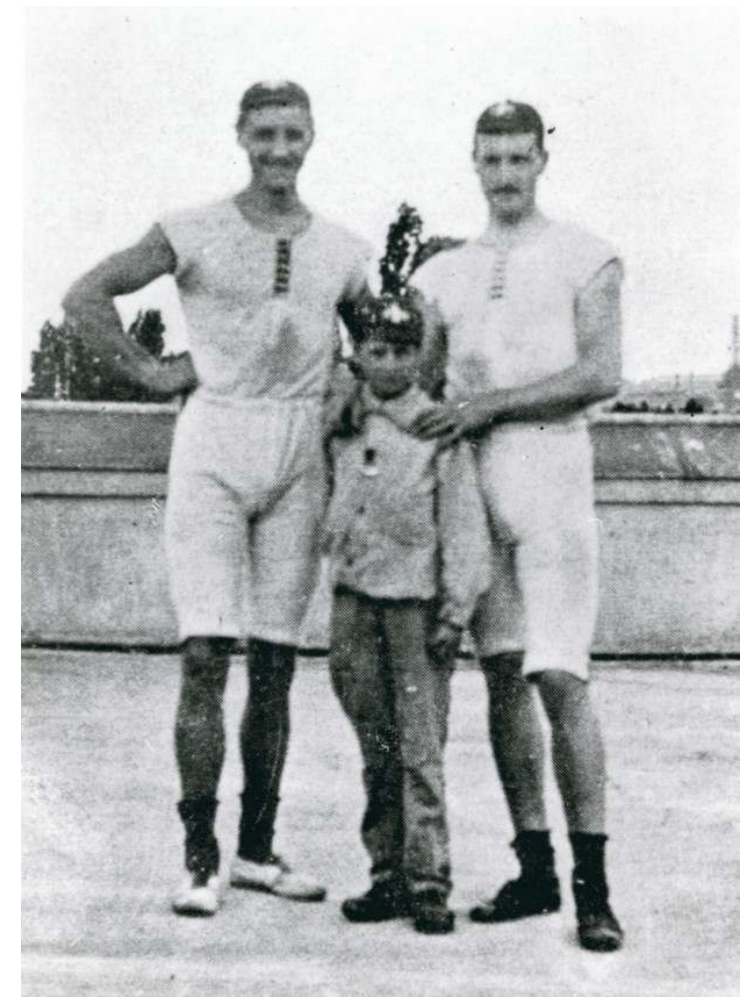

\section{Coda}

Nos hemos enfocado en festividades masivas que, lejos de subvertir plenamente las jerarquías en una detención del orden establecido (en una versión próxima al carnaval que describe Bajtin), constituyen pequeños pasos para el desarrollo del capitalismo. Nos queda aún girar un poco más el caleidoscopio para apreciar la infinitud de figuras que le caben a este escenario.

Ya Blaise Pascal en sus Pensamientos se pregunta por los entretenimientos públicos e incluso por el rechazo al aburrimiento. Es desde allí que sostiene que a los pobladores que se reúnen "no cabe censurarlos debidamente; su falta no consiste en que busquen el tumulto, si no lo buscan más que como un divertimento; lo malo es que lo buscan como si la posesión de los bienes buscados fuera a hacerles verdaderamente felices, en lo cual se tiene razón de acusar a esta búsqueda de vanidad; de suerte que en todo ello, tanto lo que censuran como los censurados no entienden la verdadera naturaleza del hombre" ${ }^{25}$.

El río visitado por las masas no es precisamente esa fluencia que se contempla en tono bucólico, ni la naturaleza que responde y reniega de la ciudad. No es el río en el bosque que recorre Henry David Thoreau en su Diario del viajero y es halagado: "río manso, manso río, / raudo se desliza tu caudal" ${ }^{26}$. Hablamos en este escrito del río con inicios de contaminación y usado también para un primigenio turismo, el río dispuesto para el espectáculo. No obstante, hemos encontrado diferentes maneras por las que las figuras de los niños nos permitieron alejarnos de los juicios simplificadores al respecto. La niñez, que nos guió a lo largo de este recorrido, también puede ser asumida como la infancia, como la potencia de lo nuevo, para permitirnos aportarle, desde rincones inexplorados, 
una coloración diferente a nuestras conjeturas. Es un sendero que no tiene direcciones definidas y que propone compartir permanentemente las inquietudes alrededor de un vínculo sin fronteras fijas.

\section{NOTAS}

1. Francisco D. Segovia, Del pasado entrerriano. Cuantos y anécdotas paranaenses, Paraná, colección "Cuadernos de las orillas", EDUNER, 2017, p. 58.

2. Recordemos que Huizinga define al juego como "una convención sobre reglas válidas únicamente dentro de unos límites bien marcados, pero de absoluta obligatoriedad; sin fin utilitario alguno, pero con un efecto de bienestar, de abandono, de alegría y de elevación". Si bien Huizinga adopta una postura un tanto extrema al afirmar que la cultura misma surge en forma lúdica, su definición de juego se vuelve productiva para nuestros propósitos. Johan Huizinga, Homo ludens, trad. Eugenio Imaz Echeverría, Madrid, Alianza, 2007, p. 238.

3. Giorgio Agamben, Signatura rerum, trad. Flavia Costa y Mercedes Ruvituso, Buenos Aires, Adriana Hidalgo, 2008, p.33.

4. Guy Debord, Society of spectacle, Londres, Rebel Press, 2004, p. 7.

5. Daniel Bensaïd considera al espectáculo como el último estadio del fetichismo de la mercancía y ubica al texto de Debord en una serie de escritos publicados en la década de 1960 que destacan las consecuencias nocivas del capitalismo tardío, involucrando la mercantilización de la cultura. Así, se puede hablar de libros como la Crítica de la razón dialéctica de Jean-Paul Sartre de 1961, Las cosas de Georges Pérec de 1965, el segundo volumen de la Crítica de la vida cotidiana de Henri Lefebvre y El hombre unidimensional de Herbert Marcuse de 1967, el mismo año de publicación de la obra de Debord. Cfr. Daniel Bensaïd, Le spectacle, stade ultime du fétichisme de la marchandise, Clamency, Lignes, 2001.

6. Giorgio Agamben, Profanaciones, trad. Flavia Costa y Edgardo Castro, Buenos Aires, Adriana Hidalgo, 2009, p. 1079.

7. Ibídem, p. 101.

8. Jacques Rancière, El espectador emancipado, trad. Ariel Dillon, Buenos Aires, Manantial, 2010, pp. 19-20.

9. No obstante, podemos poner en cuestión las apreciaciones precedentes si buscamos los aportes de Jonathan Crary, quien señala claras diferencias entre las acciones del espectador y del observador: "a diferencia de spectare, raíz latina de 'espectador', la raíz de 'observar' no significa literalmente 'mirar a': "Un observador es, sobre todo, alguien que ve dentro de un conjunto determinado de posibilidades, que se halla inscrito en un sistema de convenciones y limitaciones" (Jonathan Crary, Las técnicas del observador. Visión y modernidad en el siglo XIX, trad. Fernando López García, Murcia, Cendeac, 2008, p. 21). El acto de observar no se produce fuera de las relaciones que establecen las coordenadas de su funcionamiento y sus alcances. Desde la postura de Crary, la configuración histórica del observador moderno se condice con la proliferación de dispositivos técnicos de visión de inicios y mediados del siglo XIX. Así, la fotografía, el cine y los diferentes experimentos ópticos llevarán a una modificación sin precedentes del régimen escópico.

10. Juan A. Vilar, Hacia la derrota federal. La Confederación Argentina 1852-1862, Paraná, EDUNER, 2017, p. 79. 
11. Frédéric Gros, Andar, una filosofía, trad. Isabel González Gallarza, Madrid, Titivilus, 2014, p. 272. Disponible en http://assets.espapdf.com/b/Frederic\%20Gros/Andar,\%20una\%20filosofia\%20 (2542)/Andar,\%20una\%20filosofia\%20-\%20Frederic\%20Gros.pdf. Consultado el 8 de febrero de 2017.

12. Charles Baudelaire, Obras, trad. Nydia Lamarque, Madrid, Aguilar, 1987, p. 536.

13. José Martí, La Edad de Oro, Buenos Aires, Huemul, 1966, p. 146.

14. Ibidem, p. 149.

15. Rubén Darío, Viajes de un cosmopolita extremo, Buenos Aires, FCE, 2013, p. 106.

16. Ibidem, p. 210.

17. Ibidem, p. 294.

18. Walter Benjamin, El Berlín demónico. Ensayos radiofónicos, trad. Joan Parra Contreras, Barcelona, Icaria, 1987, p. 39.

19. Émile Zola, Yo Acuso. La verdad en marcha, trad. E. Castejón, Barcelona, Editorial Prensa Ibérica, 1998, p. 97-98, 129.

20. Carl Posey, The Olympic Century. II Olympiad, Londres, Warwick Press, 2015, s/p.

21. Walter Benjamin, Escritos franceses, trad. Horacio Pons, Madrid, Amorrortu, 2012, p. 201-202.

22. Susan Buck-Morss, Dialéctica de la mirada, trad. Nora Rabotnikof, Madrid, La Balsa de la Medusa, 1988, p. 354-355.

23. Luciano Wernicke, Historias insólitas de los Juegos Olímpicos, Buenos Aires, Planeta, 2012, p. 49.

24. Ibidem, p. 49.

25. Blaise Pascal, Pensamientos, disponible en línea en www.biblioteca.org.ar, 2003, p. 20.

26. Henry David Thoreau, La canción del viajero, trad. Eric Schierloh, Buenos Aires, Barba de Abejas, p. 2012, p. 22.

\section{RESÚMENES}

El presente trabajo se propone estudiar la relación del río y la ciudad a partir de la hipótesis que señala que el río tiene un momento de singular eclosión como escenario de espectáculos y diversiones para las masas en una incipiente industria cultural en 1900, año en que coinciden la Exposición Universal y los Juegos Olímpicos en la ciudad de París, adquiriendo el Sena un rol protagónico. En primer lugar se desplegarán los interrogantes iniciales del planteo. Luego se estudiará el lugar del río en la Exposición Universal con la lectura de las crónicas de Rubén Darío. A continuación, se establecerán relaciones con el desarrollo de los Juegos Olímpicos en el mismo año y en el mismo escenario. A partir de allí se expresarán propuestas para continuar con el debate.

Ce travail se propose d'étudier la relation du fleuve et la ville à partir de l'hypothèse qui remarque que le fleuve a un moment d'éclosion singulière pour une scène de spectacles et de divertissements pour les masses dans une industrie naissante culturelle en 1900, l'année dans laquelle coïncident l'Exposition Universelle et les Jeux Olympiques dans la ville de Paris, en acquérant la Seine un rôle d'importance. En premier lieu les questions initiales se déploieront. Tout de suite on étudiera le lieu du fleuve dans l'Exposition Universelle avec la lecture les chroniques de Rubén Darío. Ensuite, des relations s'établiront avec le développement des Jeux Olympiques dans la même année et dans la même scène. À partir de là des propositions s'exprimeront pour continuer avec le débat. 
The present work proposes to study the relation of the river and the city from the hypothesis that indicates that the river takes a moment of singular appearance as a scene of spectacles and amusements for the masses in an incipient cultural industry in 1900, year in which the Universal Exhibition and the Olympic Games coincide in the city of Paris, acquiring the Seine leading role. Firstly, the initial questions will be spread. Then the place of the river will study in the Universal Exhibition with the reading Rubén Darío's chronicles. Later, relations will be established by the development of the Olympic Games in the same year and in the same scene. From there offers will express to continue with the debate.

ÍNDICE

Palabras claves: ciudad, río, exposición universal, juegos olímpicos.

\section{AUTOR}

\section{ALEXIS A. CHAUSOVSKY}

Universidad Nacional de Entre Ríos, Argentina

alexchaus@hotmail.com 